\title{
Serine/Threonine-Protein Kinase Nek3
}

National Cancer Institute

\section{Source}

National Cancer Institute. Serine/Threonine-Protein Kinase Nek3. NCI Thesaurus. Code C104846.

Serine/threonine-protein kinase Nek3 (506 aa, 58 kDa) is encoded by the human NEK3 gene. This protein plays a role in morphogenesis and polarity of neurons. 